\title{
Practices and Challenges of Postgraduate Diploma in Teaching (PGDT) Programme: The Case of Haramaya University
}

\author{
Koye Kassa ${ }^{1}$, Yonas Amdemeskel ${ }^{2}$ \\ ${ }^{1,2}$ Lecture, Haramaya University, College of Education and Behavioral Sciences
}

\begin{abstract}
This article examines the practice of Postgraduate Diploma in Teaching (PGDT) of Haramaya University (Eastern Ethiopia particularly Somali Region and East and West Hararghea Zones of Oromia Region).The paper focused on the selection and admission processes of candidates, the classroom instruction and the practicum work of student teachers in the mentioned areas. To this end, instructors of Haramaya University who taught the PGDT students, student teachers, Regional Education Bureaus (REBs) and Zone Education Departments (ZEDs) were participated in the study. Multiple instruments with multiple sources were used in data collection in the following order: questionnaires for instructors and student teachers, interviews with REB and ZED personnel, and document analysis for $\mathrm{HU}$ students' entrance exam results and attendants of mentor training and tutorial and reflection session. The data collected were analyzed using numbers, percentage, means and weighted mean and narration and presented in tables and figures. Factors for the challenges of implementing PGDT in line with the guidelines were; change of modality, lack of understanding between Ministry of Education (MoE) and REB, lack of ownership from MoE as well as from REB, low motivation of student, shortage of appropriate mentors, absence of organized teaching materials. The study showed that the practice of PGDT is against the guidelines, instructors, students and experts believed that it should not be given in summer modality. The study wrapped up with some plausible recommendations that alleviate or minimizes the effect of barriers.
\end{abstract}

Keywords: curriculum, Classroom instruction, practice, challenges, practicum

\section{Introduction}

\subsection{Backgrounds of the Study}

Education is universally acknowledged in vast body of literature as an essential element in the process of national development (UNESCO, 1997; UNESCO, 2005; TGE, 1993; GCE, 2000; Psacharopoulos, 1985; Lockheed and Verspoor, 1991). It unlock human potential and helps individuals to better understand the world in which they live, to address the complexity and interconnectedness of problems such as poverty, wasteful consumption, environmental degradation, urban decay, population growth, gender inequality, health, conflict and the violation of human rights that threaten our future and also seeks to empower people to assume responsibility for creating a sustainable future.

Today, with a great understanding of the function that education has to the society and to the country as whole, Ethiopia is striving to expand education at all levels (primary, secondary and tertiary education) with the intention to transform society through education. To this end, new goals of access, equity, quality and efficiency have been articulated/ formed at national level in Ethiopian education and training. To respond to this growing rapidity changing demand of education, Teacher preparation has also changed in haste in the past decades. In similar manner, the Ethiopia teacher's development program has passed through different reforms and improvements.

Although, the purpose of teacher education is to produce effective practicing teacher (George.et al., 2000) the question of how trainees can best be prepared to become effective classroom practitioners. Therefore, in Ethiopia new teacher education program is designed to strengthen the quality of teaching at secondary school level and fill gaps identified in the knowledge, practice and commitment of teachers prepared through programs (MoE, 2007, MoE, 2009b). The new program is also intended to bring the preparation of secondary teachers in line with international standards which comprise a degree in a relevant subject followed by a professional qualification.

Though the program is being implemented as of July 2011 in ten universities of the country, its implementation is not effective as proposed. According to the writer's experience in Haramaya University, College of Education and Behavioral Sciences as instructors of the PGDT students, one of the writers of this article served as a coordinator of the program, as trainers of mentors, and coordinator and facilitators of the winter tutorial and reflection sessions of student teachers, the program has passed through many challenges.

Aspiring quality according to the framework from the program within these challenges is something difficult and that needs critical analysis and follow up for intervention. Thus, having a close experience with the program initiated us to come up with the research topic to contribute some in analyzing the practices and challenges of postgraduate diploma in teaching (PGDT); the case of Haramaya University and recommend some intervention areas.

To this end, the following research questions were developed:

1)How the selection and admission process of PGDT candidates had taken place in relation to the criteria and steps designed in Haramaya University?

2)How do the instructors perceive the summer modality of PGDT program in Haramaya University? 


\section{International Journal of Science and Research (IJSR) \\ ISSN (Online): 2319-7064}

Index Copernicus Value (2013): 6.14 | Impact Factor (2015): 6.391

3)To what extent the practice of PGDT practicum is implemented effectively in the mandate areas of Haramaya University?

\subsection{Objectives the Study}

The general objective of this research was to analyze the practice of PGDT at Haramaya University. Specifically, this research attempted to:

- Analyze the selection and admission process of PGDT candidates in relation to the criteria and steps designed in Haramaya University.

- Examine the perception of instructors towards the summer modality of PGDT program in Haramaya University.

- Investigate the effectiveness of PGDT practicum implementation in the mandate areas of Haramaya University.

- Recommend possible intervention mechanisms that help improve the implementation of the PGDT program.

\section{Research Methodology}

\subsection{Sources of Data}

The data sources of this research were PGDT coordinator at HU, instructors of HU who delivered PGDT courses, PGDT students (student teachers) who attended the winter tutorial and reflection sessions, experts from Somali REB and West and West Hararghe zone.

\subsection{Sample and Sampling Techniques}

All PGDT students who attended the winter tutorial and reflection sessions (257) and seventeen Haramaya University instructors who gave courses to the PGDT students were included using availability sampling. Purposive sampling was used for REBs and ZEDs experts since they are direct responsible personnel

\subsection{Data Collection}

This research employed both primary and secondary data. The primary data were collected from student teachers, the instructors, Somali Regional Education Bureau (REB) and Zonal Education Department (ZED) and HU PGDT coordinator. The secondary data were obtained from $\mathrm{HU}$ documentations. Questionnaire was used to collect information from student teachers and the instructors and interview method was employed to collect data from the PGDT coordinator, Somali REB and West and West Hararghe Zone.

\subsection{Method of Data Analysis}

In this research, the major data analysis methods were frequency, percentage, and mean for quantitative data and narration of reflections and interviews for qualitative data. Tables and graphs were used to present the data in a selfexplanatory manner.

\section{Results and Discussions}

This part presents the results of the primary and secondary data in relation to the basic questions. The findings are presented in tables, figures and statements as needed according to the type of data collected and finally the basic results are summarized.

\subsection{Data about the Selection and Admission Processes of the PGDT Students}

According to the PGDT program coordinator of the, Haramaya University, though the PGDT program was supposed to be started in regular winter season (October to June) in 2010/11 academic year, the final decision was made in April 2011. The decision reveals that in July 2011 about 10,000 candidates would be joined to seven selected teacher education universities (Addis Ababa, Bahirdar, Dilla, Haramaya, Hawassa Jimma and Mekelle). Meanwhile MoE announced that the number of teacher training universities is increased to ten (Wollega, Wollo and Walayta were added). These 10,000 candidates are based on the needs of the REB to employ in $2011 / 12$ academic year in secondary schools. This urgent need was one of the critical factors that forced us to start the programme in summer modality.

After the universities had been selected, the MoE sent a letter to all universities in the country that had graduating batch to register prospective graduates with CGPA of 2.33 or 2.5 major GPA and above and who are willing to be teachers. During registration candidates were given a form to mark their choices of working regions in rank order. After registration MOE again called university and Regional Education Bureau representatives to select and place students from June 13-18/ 2011.

Initially, it was decided that candidates will be selected using CGPA, Entrance Exam and Interview results. The selected universities were expected to enroll 1000 candidates from 2,000 candidates through competition. From the 2000 the top 1000 (according to the result of entrance exam, interview result and CGPA) will be selected and registered.

As mentioned earlier, the admission criteria to the PGDT were defined. Unfortunately, when the representatives of the universities and Educational Bureaus arrived to the MOE:

- The actual need for the Regions was only about 3412.

- Some of the universities registered based on CGPA only, some others with major GPA only.

- The remaining time for placement, competing and selection was too short (about 20 days).

- Even some the regions didn't report their actual needs (e.g Tigray and Oromia)

Following these inconveniencies, the participants of the meeting started an argument on the why of the reduction of the number (needs of regions) as well as the problems related to the placement and selection process within that short time.

After two days discussion the participants came up with the following agreement. 


\section{International Journal of Science and Research (IJSR) \\ ISSN (Online): 2319-7064}

Index Copernicus Value (2013): 6.14 | Impact Factor (2015): 6.391

1) Students only with CGPA of 2.5 and above should be included except physics graduates (for physics CGPA 2.33 and above because of the shortage).

2) Students should only be selected by their CGPA without Entrance Exam and Interview result.

3)Quota should be given for universities to determine the number of candidates who should be sleeted based on the number of graduated they registered and brought.

4)Each university representative should take the top candidates according to the quota given and select resaves equal in number with the top selected.

Based on the agreement, each university selected and submitted the list of selected and reserve candidates for each subject. Consequently, university and REB representatives were grouped and assigned to different subject areas to place the candidates to different regions based on their ranked choices. The placement process took about three days. During the three days some of the groups finalized but the majority couldn't finish and they left it for the MOE officials (experts).

The other source of argument was that MOE ordered the universities to conduct the entrance exam. The university representatives resisted the idea of entrance exam because the result is not used for selection purpose. But the MOE justified that though we couldn't use the exam for selection purpose, the result will serve us as baseline data and for validation purpose. Finally, it was decided that all universities should give the entrance exam at the same day and time before class is started and the soft copy of the exams booklets and their answer keys were given to the university representatives. The class was supposed to be started on July 8/2011. This description tells us that the selection process was not in line with the actual guideline.

Following the meeting at MOE Haramaya University, College of Education and Behavioral Sciences was making the necessary preparation to admit students. The college assigned a coordinator under the Department of Pedagogical Sciences, organize exam and programme committees each had three members. In addition to the preparation made at the college level, discussions were made between top management of the university, the students' service and the university registrar.

MOE, after finalizing the regional placement of candidates, assigned the selected students into the ten selected universities. Even if class was supposed to be started on July $8 / 2011$ after conducting the entrance exam, the list of students reached to the universities very lately. For instance, Haramaya University CEBS got the list from other universities through e-mail after July 12/2011. Some universities didn't receive the list until July 22/2011for example Hawassa, Welayta Sodo universities.

On the other hand, the small notice from MOE together with the list of students stated that universities should start class on July12/2011. But there were many challenges that universities have faced at this time

- Universities didn't receive the list of students at the same time.

- The assigned students couldn't know their placement in time.

- Students were unable to report to the universities at the right time.

- Entrance exam couldn't be conducted before class in all universities.

- Entrance exam couldn't be conducted at the same time in all universities.

- All students reported to universities didn't take the entrance exam.

- Students were placed in to more than one university.

- There were students who were selected but not assigned to any university.

- Students who passed for higher education teaching as G.As were also assigned to universities and finally they were replaced by others very lately.( about 44 students were cancelled and replaced by others after they registered and started class)

- Some students were not graduated up to July 26/2011 for instance, Axum University.

- The placement was against the agreement reached on the June meeting at MOE.

With these all challenges, the HU CEBS announced students' placement as soon as it received their list and reported some problems to MOE. After announcing the placement the college started registration for about ten days. After ten days registration the college organize orientation session about the program, the entrance exam date and class starting date.

The exam schedule was posted for students with the exam place, group and list of invigilators. Though the entrance exam was conducted according to the schedule peacefully, all registered students were not able to sit for it. Besides, students who were registered after the entrance exam date didn't take the exams.

To witness this, the total number of PGDT students joined Haramaya University was 295. Of them only 226 took the entrance exam. The rest of them didn't take the entrance exams because of one they came late two some were went back for their graduation. Students' result in the three exams is summarized in table 1 below. 


\section{International Journal of Science and Research (IJSR) \\ ISSN (Online): 2319-7064 \\ Index Copernicus Value (2013): 6.14 | Impact Factor (2015): 6.391}

Table 1: The Mean Entrance Exam Result of the Students at Haramaya University

\begin{tabular}{|l|c|c|c|c|c|c|c|c|c|c|}
\hline \multirow{3}{*}{ S. No. } & Subject Area of students & \multicolumn{9}{|c|}{ Number of students for each exam types } \\
\cline { 3 - 12 } & & \multicolumn{3}{|c|}{ Major Subject area } & \multicolumn{3}{|c|}{ English(45) } & \multicolumn{3}{c|}{ Aptitude(36) } \\
\cline { 3 - 12 } & & Max. & Min. & Mean & Max. & Min. & Mean & Max. & Min. & Mean \\
\hline 1. & Biology $(\mathrm{N}=30)$ & 58 & 16 & $* * 41.41$ & 31 & 11 & 20.14 & 21 & 4 & 15.07 \\
\hline 2. & Chemistry(N=31) & 29 & 13 & 20.26 & 31 & 9 & 20.03 & 21 & 10 & 17.81 \\
\hline 3. & English(N=24) & 41 & 10 & $* 25.63$ & - & - & --- & 27 & 13 & $* 18.71$ \\
\hline 4. & Geography(N=29) & 44 & 28 & $* * 37.03$ & 29 & 14 & 22.17 & 29 & 11 & $* 18.79$ \\
\hline 5. & History(N=36) & 37 & 18 & $* * 29.61$ & 32 & 11 & $* 23.81$ & 29 & 13 & $* 19.64$ \\
\hline 6. & Mathematics(N=32) & 20 & 5 & 11 & 27 & 9 & 17.438 & 22 & 2 & 15.91 \\
\hline 7. & Physics(N=21) & 27 & 12 & 19.19 & 33 & 10 & 18.05 & 21 & 9 & 16.52 \\
\hline 8. & Sport science $(\mathrm{N}=23)$ & 34 & 11 & 23.091 & 28 & 8 & 14.77 & 20 & 7 & 14.86 \\
\hline
\end{tabular}

* refers to nearly 50\%, ** refers to greater than 50\%, without * refer to below $50 \%$

The above table shows that, Geography, History, Biology and Chemistry students scored a little bit above 50\% and the rest scored below 50\% in major area subjects (the graduated in B.A and B.SC). In English language exam, only History students scored nearly above $50 \%$ and the rest of them scored below 50\%. And in aptitude exam, History, Geography, and English (social science) students scored nearly above average ( $50 \%$ of the items), the rest scored below $50 \%$ of the exams.

Table 2: Students' Percentage Score of Entrance Exam Result

\begin{tabular}{|c|c|c|c|c|c|c|c|c|c|c|c|c|}
\hline \multirow{3}{*}{$\begin{array}{l}\text { Subject Area of } \\
\text { students }\end{array}$} & \multicolumn{12}{|c|}{ Number of students for each exam types } \\
\hline & \multicolumn{4}{|c|}{ Major Subject area } & \multicolumn{4}{|c|}{ English } & \multicolumn{3}{|c|}{ Aptitude } & \multirow[b]{2}{*}{ Total } \\
\hline & $\begin{array}{c}<50 \\
\%\end{array}$ & $\begin{array}{l}>=50 \% \\
<75 \%\end{array}$ & $\begin{array}{l}75 \% \& \\
\text { above }\end{array}$ & Total & $\begin{array}{c}<50 \\
\%\end{array}$ & $\begin{array}{l}>=50 \% \\
<75 \%\end{array}$ & $\begin{array}{l}75 \% \& \\
\text { above }\end{array}$ & Total & $\begin{array}{c}<50 \\
\%\end{array}$ & $\begin{array}{l}>=50 \% \\
<75 \%\end{array}$ & \begin{tabular}{|l}
$75 \% \&$ \\
above
\end{tabular} & \\
\hline Biology & 6 & 21 & 3 & 30 & 22 & 8 & 0 & 30 & 21 & 9 & 0 & 30 \\
\hline Chemistry & 20 & 11 & 0 & 31 & 20 & 11 & 0 & 31 & 13 & 18 & 0 & 31 \\
\hline English & 21 & 3 & 0 & 24 & --- & $\begin{array}{ll}---- \\
\end{array}$ & $\begin{array}{l}---- \\
---\end{array}$ & 24 & 11 & 12 & 1 & 24 \\
\hline Geography & 0 & 15 & 14 & 29 & 14 & 15 & 0 & 29 & 12 & 16 & 1 & 29 \\
\hline History & 6 & 30 & 0 & 36 & 13 & 23 & 0 & 36 & 12 & 23 & 1 & 36 \\
\hline Mathematics & 29 & 3 & 0 & 32 & 26 & 6 & 0 & 32 & 24 & 8 & 0 & 32 \\
\hline Physics & 16 & 5 & 0 & 21 & 18 & 3 & 0 & 21 & 14 & 7 & 0 & 21 \\
\hline Sport science & 14 & 9 & 0 & 23 & 21 & 2 & 0 & 23 & 17 & 6 & 0 & 23 \\
\hline Total & 112 & 97 & 17 & 226 & 134 & 68 & 0 & 202 & 124 & 99 & 3 & 226 \\
\hline
\end{tabular}

Source $H U, C E B S$ file

**Note: the numbers of questions for English and aptitude were 45 and 36 respectively. The number of questions for major subject areas are Biology=75, chemistry 45, English=70, Geography=50, History=50, Mathematics $=30$, Physics $=45$ and Sport science $=50$.

As can be seen from table 2 above, in major subject area, except Geography and Biology students no other stream student scored $75 \%$ and above. Even from Geography 14 $(42 \%)$ and from Biology only $3(10 \%)$ scored $75 \%$ and above. Majority of History, Geography, and Biology students scored $50 \%$ and above but below $75 \%$. The majority of Chemistry, English, Mathematics, Physics, and Sport Sciences students scored below $50 \%$.

In English language exam, no one scored $75 \%$ and above. Majority of History, and Geography students scored $50 \%$ and above but below $75 \%$. The majority of Biology, Chemistry, Mathematics, Physics and Sport sciences students below $50 \%$.

In Aptitude exam, no one scored $75 \%$ and above. Majority of History, Chemistry, English and Geography students scored $50 \%$ and above but below $75 \%$. The majority of Biology, Mathematics, Physics and Sport science students scored below $50 \%$.

Moreover, the data summarized in Figure 1 below revealed that in major area subjects, out of 226 examinees, 112 (49.6\%) scored below 50\%, $97(42.92 \%)$ scored above $50 \%$ but below $75 \%$ and only 17 (7.5\%) scored $75 \%$ and above. In English language, out of 202 examinees, 134 (66\%) scored below $50 \%, 68(33.66 \%)$ of students scored $50 \%$ and above but below $75 \%$ and no one scored $75 \%$ and above even students from English major couldn't reach to $75 \%$ of score point. And in Aptitude,, out of 226 examinees, 124 (55\%) scored below $50 \%, 99(43.8 \%)$ students scored 50\% and above but below 75\% and only $3(1.3 \%)$ scored $75 \%$ and above even.

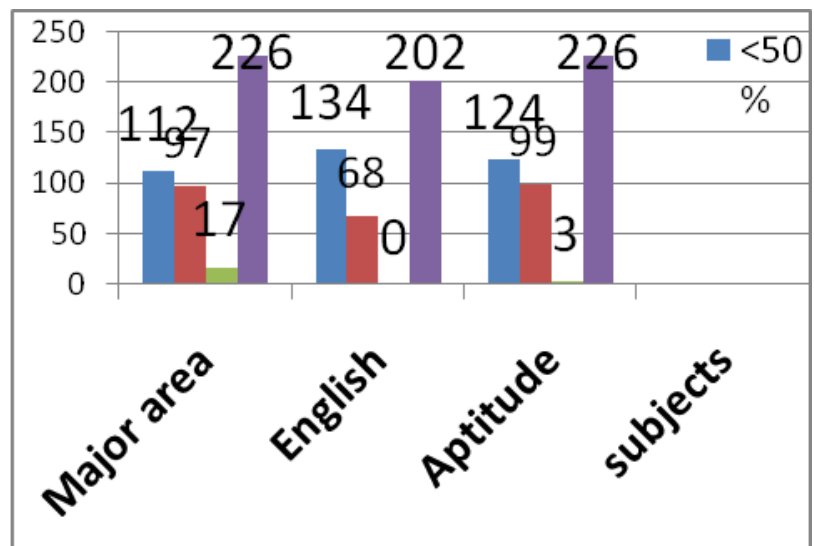

Figure 1: Summary of Entrance Exam Results across Exam Types

Source, HUCEBS file 


\section{International Journal of Science and Research (IJSR) \\ ISSN (Online): 2319-7064}

Index Copernicus Value (2013): 6.14 | Impact Factor (2015): 6.391

Table 3: Instructor Response about PGDT Instruction Process

\begin{tabular}{|c|c|c|c|c|c|c|c|}
\hline S.No. & Statements & \multicolumn{4}{|c|}{ Responses } & Weighted \\
& & SA & A & N & DA & SD & mean \\
\hline 1. & Adequate preparation time was given for instructors & 1 & 1 & 1 & 9 & 5 & 2 \\
\hline 2. & Classrooms were convenient for student centered learning & 3 & 5 & 2 & 4 & 3 & 3 \\
\hline 3. & Students devoted much for home assignments & 0 & 1 & 2 & 7 & 7 & 2 \\
\hline 4. & Students were motivated to learn & 0 & 0 & 2 & 5 & 10 & 2 \\
\hline 5. & Students were open for application of ALMs & 1 & 1 & 1 & 11 & 3 & 2 \\
\hline 6. & Students attendance was high & 4 & 8 & 0 & 3 & 2 & 4 \\
\hline 7. & Students were highly engaged in the classroom tasks & 0 & 2 & 2 & 11 & 2 & 2 \\
\hline 8. & Students were well disciplined & 2 & 8 & 4 & 2 & 1 & 3 \\
\hline 9. & The class sizes were convenient to apply ALMs. & 7 & 3 & 4 & 2 & 1 & \\
\hline 10. & The modality designed was appropriate & 1 & 2 & 3 & 4 & 7 & \\
\hline 11. & Students welcomed the application of continuous assessment & 0 & 2 & 2 & 9 & 4 & 2 \\
\hline 12. & Institutional support given for instructors was encouraging & 1 & 1 & 2 & 7 & 6 & 2 \\
\hline
\end{tabular}

From the above descriptions, we can understand that half of the students couldn't perform even $50 \%$ in their major area, about $66 \%$ of them scored below $50 \%$ in English language which is the teaching language at the secondary school and $55 \%$ of them scored below $50 \%$ in aptitude exam. This may be because of the reason students knew that the entrance exam didn't have any contribution for their admission or it might be because of the time they had to make the necessary preparations.

All these facts witness that in one hand, the selection and admission processes were not performed according to the guidelines. This means, the entrance exam was not conducted for all of the candidates and its result was not considered to admit the candidates. The only criterion used was their CGPA. The placement and registration of the students was full of mess and disorganized. On the other hand, all of the students didn't sit for the entrance exams and the exam prepared and administered didn't play the role expected of it. The students who joined to the program are not appropriate in knowledge competence as well as preference of the profession though their CGPA are good. From this one can say all of the candidates admitted were not competent and interested in the profession which is against the assumption of the program. Thus, it will be mandatory to fix to the selection criteria to admit students.

\subsection{Data about the Instructional Processes of the PGDT Program at $\mathrm{HU}$}

Primary data about the effectiveness/appropriateness of the instruction process in the first term of the program were taken from instructors and the PGDT coordinator. They are presented accordingly as follows.

Regarding the responses of instructors, there were about twenty instructors engaged in the delivering the five courses. All of them were males and by specialization five were from Psychology, two from Curriculum two from Special Needs Education, four from English and the rest were Biology, Chemistry, Geography, History, Mathematics, Physics and Sport Science one from each.

Out of the 20, the researchers could get only 14 instructors and distribute questionnaire having three parts; background information, scale statements and open ended questions.
The scale has five agreement level alternatives SA, A, N, DA and $\mathrm{SD}$ where $\mathrm{SA}=$ Strongly Agree, $\mathrm{A}=$ Agree, $\mathrm{N}=$ Neutral, $\mathrm{DA}=$ Disagree and $\mathrm{SD}=$ Strongly Disagree. Finally the responses are summarized and the weighted mean is calculated (the value given for $S A=5, A B=4, N=3, D A=2$ and $S D=1$ ).

The above table revealed that the instructors agreed that class sizes were convenient to apply ALMs (mean=4). Students attendance was high (mean $=4$, the instructors mentioned that students attended because of instructors regularly take attendance and give quizzes), classrooms were convenient for student centered learning (mean=3) and Students were well disciplined (mean 3 ) for the rest of the items they disagreed. Meaning, they believed that adequate preparation time was not given for instructors, students were not open for application of ALMs, students did not devote much for home assignments, Students were not motivated to learn, Students were not highly engaged in the classroom tasks, the modality designed was not appropriate, students did not welcome the application of continuous assessment and institutional support given for instructors was not encouraging. Instructors were requested their opinion on the summer modality of the program. Consequently, all of them except one suggested that the program should be given in regular program.

Regarding the strong sides of the program the instructors forwarded the following; the intention to take teachers by their interest, the courses ideally designed are appropriate, the class size, good program coordination and promotion of the college, good time management, commitment of the college in attempting to solve problems immediately, good motivation of instructors (in the beginning). On the other hand, they stated low motivation and interest of the students (students were not in good mood), late starting of the class, lack of organized teaching materials for the courses, much confusion of students about the program, time was inconvenient to practical attachment, not well organized, lack of appropriate awareness about the program on both students and instructors side, it was too ambitious, lack of adequate and timely incentive for instructors, the time was not appropriate for both students and instructors as limitations of the program.

The suggested recommendations by the instructors to alleviate the limitations include the program should be 


\section{International Journal of Science and Research (IJSR) \\ ISSN (Online): 2319-7064}

Index Copernicus Value (2013): 6.14 | Impact Factor (2015): 6.391

delivered in regular that lets student practice, students should get deployed and paid salary, advance preparation of course materials, the program should be revised by stalk holders consultation, instructors should get appropriate understanding of the program, selection criteria shall be respected, MoE needs to give clear direction and make follow up to make sure that stakeholders play their roles.

In the PGDT framework it was stated that the delivery of courses would apply active learning methods and students' performance would be assessed continuously using different tools according to the performance areas of students to be assessed. But in the actual processes though the class size and the classrooms were appropriate to apply use ALMs and continuous assessment, students were not motivated and interested enough to do so.

Regarding the process of PGDT program, Coordinator at Haramaya University reflected that his institution registered about 295 students from eight subject areas graduated from different universities and would be employed to five Regional Education Bureaus namely Tigray, Afar, Oromia, Somali and SNNPR (Refer to table 4). After taking the entrance exam, students started class in a block mode for two courses (Psychological Foundation of Learning and Development and Curriculum for Secondary School Instruction) and in linear mode for one course (English for Secondary School Teaching and Learning). This means it was recommended from MOE that the two courses should be completed in the first six weeks (up to mid of August) and the rest two courses (Teachers as Reflective Practitioners and Subject Area Methods I) should be given in the next six weeks; mid August to end of September where as English for Secondary School Teaching and Learning was given for the whole three months.

Not only classroom teaching was started late but there were a lot of problems that affect students' performance. To mention some:

Lack of organized teaching materials, low motivation of students, poor attendance of students, lack of ownership of the program from MOE and REBs side, poor communication between universities and MOE, poor communication between REBs and MOE, late assignment of students who replaced those who passed for Higher Education Instructor, late coming of students to register, students were unable to attend fully the block courses because of shortage of time, confusion of students about the program especially related to employment and salary and budget for students service (health), budget for instructors' payment and the like.

Besides these problems, students raised series questions about their date of employment and their July, August and September 2011 salary and stopped class for half a day. With clear discussion with the students' representatives and the president of the university, the dean of the college and the PGDT coordinator, the students were convinced to raise their questions peacefully and continue their education. At that serious time, MoE couldn't respond to and enforce REBs to react to the question of the students' recruitment process and salary.
Regarding the completion rate of the first term of the PGDT program, the PGDT coordinator explained that, with all those challenges, the first term was completed at the end of September 2011. At the beginning though a total of 295 students were registered, only $\mathbf{2 8 3}$ could complete the term training and their list is sent to the respective working regions. This means 12 were dropped out for different reasons. Of them 9 were assigned for Afar, 12for Oromia, 16 for South Nations Nationalities and Peoples Region (SNNPR), 233 for Somali and the rest 13 were for Tigray Regional Education Bureau (for the details refer to table 4).

As discussed above, the information from the PGDT program coordinator and the instructors clearly indicate that the instruction process was challenging. The class was started late, there was no real ownership of the program by the MoE and REBs, there were no organized teaching materials, there were confusions from instructors and students' side, students were not interested and motivated, students' attendance was poor, and the like. Thus, it is really difficult to say the program is being run according to the expectation level and will be able to produce the needed quality graduates.

\subsection{Data Regarding the Practice of Practicum Program}

\subsubsection{Regarding mentor training}

These data are based on the discussion with PGDT coordinator HU, CEBS and the college's document.

According to the Adama consultative meeting agreements, REBs were expected to send the list of mentors and tutorial centers against the list of student teachers before the students left the campus. Unfortunately, this was not done and HU, CEBS through its own effort obtained the list from Somali REB and East and West Hararghea ZEDs very late. As a result, it was not possible to give appropriate and timely training for mentors.

As of the list from Regional Bureaus and Zonal Education Departments, a total of 308 mentors were expected to get training by the university. Out of them, $193(62.66 \%)$ had taken mentor training while $115(37.34 \%)$ couldn't attend because of different reasons.

Table 5: Summary Data on Mentor Training across Regions and Zones

\begin{tabular}{|c|c|c|c|c|c|c|}
\hline No. & Region & Center & Expected & Trained & \multicolumn{2}{|c|}{ Gap } \\
\cline { 6 - 7 } & & & & & No. & $\%$ \\
\hline 1 & Somali & Cherti & 27 & 19 & 8 & 29.6 \\
\hline 2 & Somali & Moyalle & 30 & 13 & 17 & 56.7 \\
\hline 3 & Somali & Godey & 19 & 12 & 7 & 36.8 \\
\hline 4 & Somali & Jijiga & 123 & 53 & 70 & 56.9 \\
\hline 5 & Somali & Qebridehar & 7 & 3 & 4 & 57.1 \\
\hline 6 & Somali & Shinile & 25 & 20 & 5 & 20 \\
\hline 7 & Oromiya & Haramaya & 47 & 44 & 3 & 6.38 \\
\hline 8 & Oromiya & Chiro & 25 & 25 & 0 & 0 \\
\hline 9 & Afar & Awash & 5 & 4 & 1 & 20 \\
\hline \multicolumn{3}{|c|}{ Total } & 308 & 193 & 115 & 37.3 \\
\hline
\end{tabular}

To mention some:

- The selection process was not appropriate (mentors were selected by Education Bureau experts by using the teachers 


\section{International Journal of Science and Research (IJSR) \\ ISSN (Online): 2319-7064}

Index Copernicus Value (2013): 6.14 | Impact Factor (2015): 6.391

previous data, some change their places, some left the profession).

- The list of mentors that came from Somali Region Education Bureau was not complete (some of the list didn't show name of mentor, simply it said principal/supervisor, in those schools they thought there are no senior teachers).

- Most of the schools are far from the center and could not be communicated and

- Most of the school mentors come far distance (especially those from Fiqe, Warder and Degahabur to come to do not have transportation access to come to center (Jijiga).

From the table above, one can see that, in the Somali Region out of 231 , only $120(51.95 \%)$ had taken the training. From Oromia out of 72, $69(95.83 \%)$ and from Afar out of 5 mentors, $4(80 \%)$ of the mentors had taken the training. On the other hand, the data tell us that in Somali Region except Shinle zone in all the other zones required number of mentors didn't take the training. Even those who took the training were not appropriate for mentorship. On the hand, from some schools the student teachers came as mentors since they are vice principals and principals as well. This is because of the reason that in new secondary schools all assigned are the student teachers with no senior teacher. The data clearly showed us that $115(37.3 \%)$ of the required mentors didn't took the training. This also indicates that there is large number of students with trained mentors and without mentors.

\subsubsection{Data on winter tutorial and reflection}

According to the Provisional Practicum Guideline and the General Guideline of PGDT for the summer modality, it was proposed that the student teachers were supposed to come to the cluster centers and take tutorial classes for the two distance courses "School and the Society and Action Research" and to reflect their practicum I and II portfolios. Accordingly, Haramaya University arranged the program from January 30 to February $03 / 2012$ in five centers; Haramaya, Jigjiga, Chiro, Godey and Moyalle. In the program, the tutorial classes for the two distance courses and reflection sessions for practicum works were scheduled. Besides students were requested to fill in questionnaires about their general process of the program and attendances were seriously taken.

A total of 376 student teachers were expected to participate the sessions in all centers. Of them 5 were from Afar Region, 99 from Oromia and the rest 272 were from Somali Region. Among these, 257 attended the tutorial; 5 from Afar, 91 from Oromia and 161 from Somali Regions. That means from Afar all of the $5(100 \%)$, from Oromia $91(91.92 \%)$ and from Somali 161 (59.19) attended the tutorial. The numbers of attendants and absentees across Region and Zones were summarized below in table 5 .
Table 6: Tutorial and Reflection Attendants and Students with No Mentor

\begin{tabular}{|c|c|c|c|c|c|c|}
\hline No. & Region & Zone & Attendants & Absentees & Total & $\begin{array}{l}\text { Without } \\
\text { mentor }\end{array}$ \\
\hline 1 & Somalli & Afder & 10 & 23 & 33 & 5 \\
\hline 2 & Somalli & Degahabur & 13 & 5 & 18 & 10 \\
\hline 3 & Somalli & Fiqe & 9 & 18 & 27 & 7 \\
\hline 4 & Somalli & Godey & 19 & 3 & 22 & 7 \\
\hline 5 & Somalli & Jigjiga & 38 & 20 & 58 & 11 \\
\hline 6 & Somalli & Liben & 24 & 8 & 32 & 5 \\
\hline 7 & Somalli & Qebridehar & 6 & 2 & 8 & 3 \\
\hline 8 & Somalli & Shinle & 33 & 4 & 37 & 4 \\
\hline 9 & \begin{tabular}{|l|} 
Somalli \\
\end{tabular} & Warder & 9 & 29 & 38 & 9 \\
\hline 10 & Afar & Afar & 5 & 0 & 5 & 0 \\
\hline 11 & Oromiya & E/Hararge) & 45 & 3 & 48 & 5 \\
\hline 12 & Oromiya & W/Hararge) & 46 & 4 & 50 & 2 \\
\hline \multicolumn{3}{|c|}{ Total } & 257 & 119 & 376 & 68 \\
\hline
\end{tabular}

Moreover, from those who attended the tutorial and reflection sessions $68(26.46 \%)$ of the student teachers do not have mentors, $39(15.18 \%)$ of them teach in primary schools instead of secondary schools, $144(44.36 \%)$ of them had additional responsibilities such as vice director, unit leader, department head and head of different clubs, and 33 $(12.84 \%)$ of them teach subjects beyond their major subject areas. The data show that out of the 68 students without mentors, only $7(10.29 \%)$ are from Oromia while the rest 61 $(89.71 \%)$ were from Somali Region. The problem was even more severe in Degahabur, Fiqe, Qebridehar, and Warder Zones of the Region. In addition to non-availability of mentors the student teachers were assigned in primary schools instead of secondary school, they were engaged in additional responsibilities and they teach courses beyond their major subject areas. This is illustrated in the following figure below.

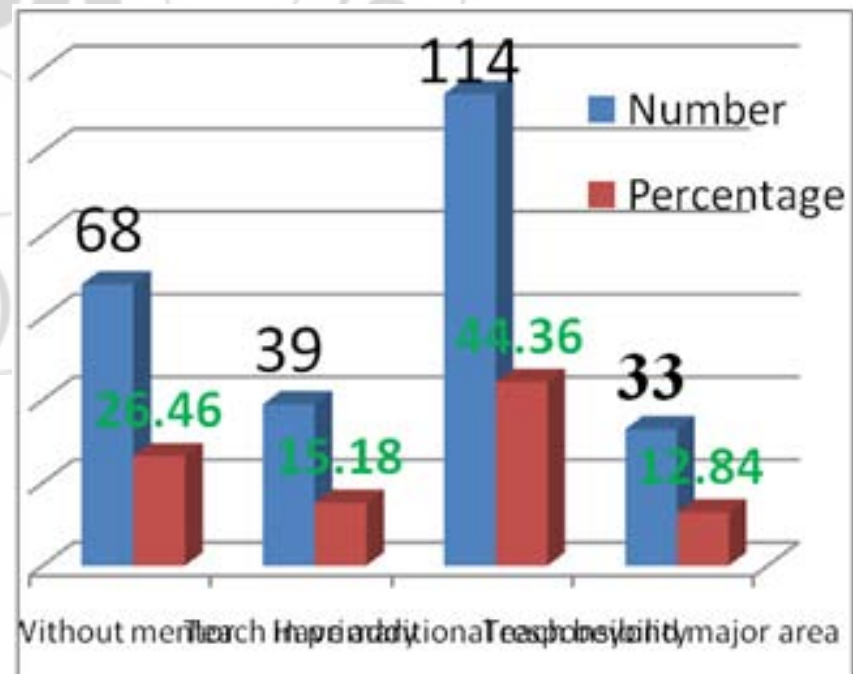

Figure 2: Summary of Students with Different Challenges

Besides the challenges student teachers faced, they were requested to rate their overall level of satisfaction(as "High', "Medium", or "Low") in their teaching job so far as teachers. The data were summarized by giving values to the rating levels (high $=3$, medium $=2$, and low $=1$ ) The Summarized data were presented below in table 7 below. 


\section{International Journal of Science and Research (IJSR) \\ ISSN (Online): 2319-7064 \\ Index Copernicus Value (2013): 6.14 | Impact Factor (2015): 6.391}

Table 7: Student Teachers' Level of Satisfaction across Working Zones

\begin{tabular}{|c|c|c|c|c|c|c|c|c|c|}
\hline \multirow[t]{3}{*}{ No. } & \multirow{3}{*}{ Zone } & \multicolumn{6}{|c|}{ Respondents } & \multirow{3}{*}{$\begin{array}{c}\text { Weighted } \\
\text { mean }\end{array}$} & \multirow{3}{*}{ Rank } \\
\hline & & \multicolumn{2}{|c|}{ High } & \multicolumn{2}{|c|}{ Medium } & \multicolumn{2}{|c|}{ Low } & & \\
\hline & & No & $\%$ & No. & $\%$ & \begin{tabular}{|l} 
No. \\
\end{tabular} & $\%$ & & \\
\hline 1 & Shinle & 16 & 53.3 & 10 & 33.3 & 4 & 13.3 & 2.4 & 1 \\
\hline 2 & $\begin{array}{c}\text { East } \\
\text { Hararghea }\end{array}$ & 21 & 46.7 & 14 & 31.1 & 10 & 22.2 & 2.24 & 2 \\
\hline 3 & Jiiiga & 11 & 28.2 & 19 & 48.7 & 9 & 23.1 & 2.05 & 3 \\
\hline 4 & $\begin{array}{c}\text { West } \\
\text { Hararghea }\end{array}$ & 16 & 34.8 & 15 & 32.6 & 15 & 32.6 & 2.02 & 4 \\
\hline 5 & Godey & 1 & 5.26 & 14 & 73.7 & 4 & 21.1 & 1.84 & 5 \\
\hline 6 & Afder & 0 & 0 & 7 & 77.8 & 2 & 22.2 & 1.78 & 6 \\
\hline 7 & Liben & 2 & 9.09 & 11 & 50 & 9 & 40.9 & 1.68 & 7 \\
\hline 8 & Fiqe & 2 & 22.2 & 2 & 22.2 & 5 & 55.6 & 1.67 & 8 \\
\hline 9 & Warder & 0 & 0 & 6 & 66.7 & 3 & 33.3 & 1.67 & 9 \\
\hline 10 & Degahabur & 0 & 0 & 7 & 58.3 & 5 & 41.7 & 1.58 & 10 \\
\hline 11 & Afar & 0 & 0 & 2 & 40 & 3 & 60 & 1.4 & 11 \\
\hline 12 & Qebridehar & 0 & 0 & 3 & 50 & 3 & 50 & 0.16 & 12 \\
\hline & $\begin{array}{l}\text { Total/ } \\
\text { and mean }\end{array}$ & 69 & 27.49 & 110 & 43.82 & 72 & 28.69 & 1.99 & \\
\hline
\end{tabular}

As can be seen from the table above, student teachers working in Shinle (2.4), East Hararghea (mean=2.24), Jijiga $($ mean=2.05) and West Hararghea (2.02) zones had better level of satisfaction according to the weighted mean result. Moreover, in Shinle 53.3\%, , in East Hararghea 34.8\%, in West Hararghea $46.7 \%$, and in Jijiga $28.2 \%$ of the student teachers had high level of satisfaction in their teaching job so far as teachers. The number and percentage of student teachers who had high satisfaction for Fiqe zone 2(22.2\%), for Godey zone 1 (5.26), and for Liben zone 2(9.09\%) whereas in the rest zones, the percentage of student teachers who had high satisfaction level is zero. Especially, student teachers in Qebridehar and Afar zones were had low level of satisfaction. The total level of satisfaction is medium (mean=1.99), though $28.69 \%$ of the student teachers had low level of satisfaction. The following figure shows the summary result of the student teachers level of satisfaction.

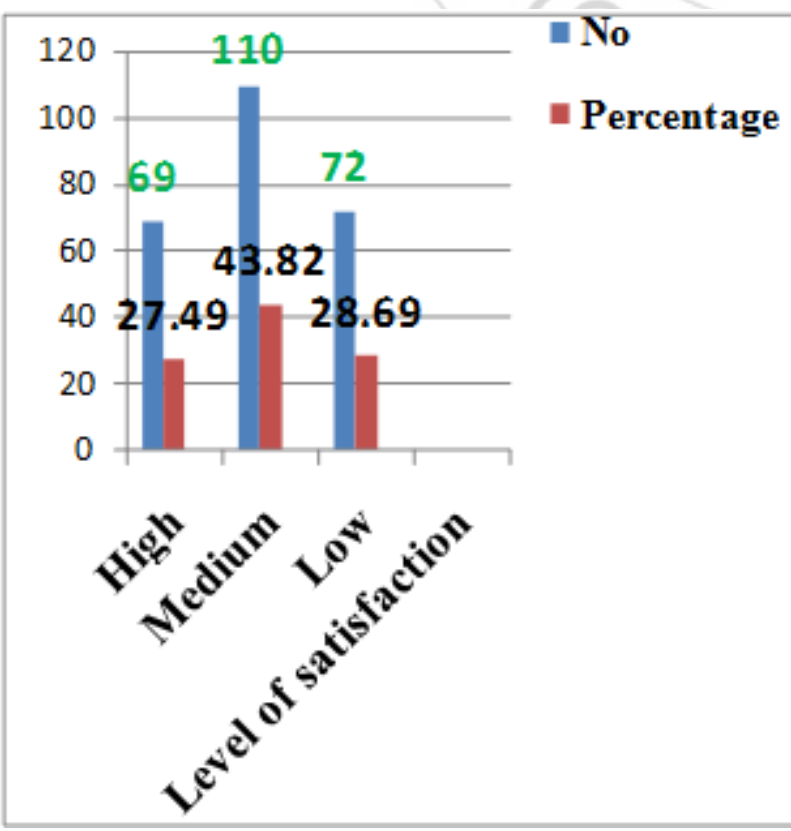

Figure 3: Summary of Student Teachers Level of Satisfaction
Figure 3 above shows that out of 251 student teachers 69 $(27.49 \%)$ had high, $110(43.82 \%)$ had medium and 72 $(28.69 \%)$ had low level of satisfaction in their teaching job so far as teachers.

From the above presentation one can understand that though the majority of the student teachers had medium level of satisfaction, there were large numbers of students who were not satisfied in their teaching job. This low satisfaction may discourage them to continue in the teaching profession, since first impression is last impression.

\subsubsection{Data from student teachers' about the practice of their practicum work}

Besides the questionnaire distributed, reflection session was conducted/arranged with student teachers who attended the tutorial and reflection. From the reflection, we could understand that regardless of the extent all of them faced challenges to adjust themselves as well as to work on their practicum. The different challenges they faced in the schools they are assigned were summarized as follows.

- They couldn't collect their salary on time. Especially in Somali region there were student teachers who didn't get their salary for the last seven months (e.g Fiq, Godey Warder Afder, Degahabur, Qebridehar, Jigjiga and Shinle Zones). They lead their life by taking supplies and goods from nearby shops in credit. Even they REB couldn't intervene to solve the problem.

- Some Woredas didn't allow July and August Salaries especially in Somali, Oromia and Afar.

- Student teachers didn't get the distance course and practicum materials from their housing universities for example those from Wellega, Hawassa and Addis Ababa universities.

- They do not have mentor support- even those who have mentors explained that the mentors are not supporting them appropriately. This is the result of lack of experienced teachers who can serve as mentors, and lack of motivation of those experienced teachers.

- They were assigned and teach in Primary out of their majors- since the instructional language for primary is the regional language (Afan Oromo and Somali languages and they do not speak them as a result they are forced to teach Amharic rather than their major. Even some of them cannot speak Amharic well leave alone to teach it.

- Because of these problems, they couldn't develop their portfolios of Practicum I and II.

One of the other problems they mentioned is their house condition. Though the majority live in rented houses, which they called "the so called houses" 31 of them reported that they couldn't get houses to be rented even. Therefore, 8 of them live in Military camps especially in Fiqe, Godey (Ferefer) and Liben (Doloado) Zones, 23 live dependently with others support such as senior staff.

\subsubsection{Reflections from Somali REB and East and West Hararghea ZEDs}

Attempts were made to get explanation why mentors were absence to the training and student teachers couldn't attend 


\section{International Journal of Science and Research (IJSR) \\ ISSN (Online): 2319-7064}

Index Copernicus Value (2013): 6.14 | Impact Factor (2015): 6.391

the tutorial and reflection sessions and about the problems student teachers mentioned from Somali Regional Education Bureau and East and West Hararghea Zones Education Departments. The discussions were made between experts working on teacher development programmes (TDP) in the mentioned offices.

In Somali Region the explanations from experts about the mentor training and student teachers tutorial seem almost similar. The major reasons for their absence were:

1)Communication Problem between the REB, ZEDs, WEOs and the schools where the mentors and student teachers belong to. The majority of the absentees are from Fiqe, Afder, Warder, Degahabur, and Godey zones. These zones are far from the center (Jijiga) and cable, air and land communications are very difficult. People from these zones travel by trucks when there is military voyage otherwise difficult to leave the areas.

2) Shortage of manpower (teachers)- student teachers were assigned to these areas because of the shortage the Region has and the increasing number of secondary schools is major reason. In the first place these student teachers shouldn't be sent to these far areas since they were not actual teachers and they were taking courses. Due to misunderstanding of the program and the shortage of manpower, the region has they were sent to those areas and where they couldn't get appropriate mentors and they couldn't come to the center as needed to come.

Regarding the salary, mentor school and house problems student teachers mentioned, the Somali REB experts reflected that the problems are there and the major reasons were: the geographical nature of the region, it is to wide, challenging and where infrastructure is poor, poor communication between the REB and zones and woredas, lack of appropriate teachers for mentorship, lack of commitment as because of absence incentive for those who work as mentors and misunderstanding of the program

The number of absentees of mentors and student teachers is not significant for East and West Hararghea zones. But the rest problems student teachers faced are common for both Somali and the two zones of Oromia. The explanation given from the two zones about the causes of the problems were:

- Poor vertical communication between MOE, REBs, ZEDs and Woreda education offices.

- Misunderstanding of the PGDT program by REBs ZEDs WEOs and schools and considering the student teachers as actual teachers

- Lack of commitment from the WEOs (especially Somali region) because of the misunderstanding

- The decentralization of the budget- though letter has been sent from MOE to REB then to ZEDs and finally to the woreda which justifies that the student teachers shall be paid their salary as of July $8 / 2011$, the woredas refused to act accordingly.

The experts from both Regions were asked about the solution to these problems. They said much but the major ones include, assigning teachers after completing their training (delivering the program in regular modality), incentives to the mentors, creating appropriate awareness up to school level and establishing effective system of vertical as well as horizontal communication and accountability of stakeholders from MoE to school level.

From all these mentioned facts, one can understand that the practicum process faces a serious problem starting from mentor selection, mentor training as well as delivering the tutorial and reflection sessions. It is also unlikely to for university supervisors to go to the student teachers place and conduct practicum III as planned earlier. Even it will be a big challenge to evaluate the student teachers for practicum and the two distance courses especially for those who do not have mentors and who didn't attend the tutorial program. Thus, it indicates that the program is not producing competent teachers as expected.

Moreover, it is clear to understand that it will be a challenge to assess these students' performance on the two distance courses and the practicum without mentors' support and without attending the tutorial and reflection session conducted in the winter semester break. As it is indicated in table 6, a total of 119 student teachers didn't attend the tutorial and most probably they are also without mentors. As a result they may come back without proper practicum portfolio and action research. The other critical issue here is that, among these 119 absentees, 100 will come back to Haramaya University and only the rest 19 are to the other teacher training universities. Thus, the major burden will be on Haramaya University than others.

\section{Conclusions and Recommendations}

\subsection{Conclusions}

As it was stated in the methodology part there were three major research questions. Since the conclusions were drawn against the research questions.

Concerning the selection and admission processes of PGDT candidates in relation to the criteria and steps designed in the guideline, it is revealed that students were admitted by using only their CGPA. The placement and registration process was full of mess and disorganized. These data witness that selection and admission processes were not appropriate rather they were against the guideline. Thus, it will be unlikely to get the secondary school teaches with the expected quality.

The majority of the instructors' perception towards the summer modality of PGDT program in Haramaya University is negative. They recognized the positive side of the 2011 summer PGDT program in the fact that it admitted students in voluntary basis and the class sizes are manageable and appropriate to conduct ALMs regardless of students' low motivation and attendance. Hence if the program is to be repeated in summer modality, advance preparation of material, allocation of budget, in time placement of students will be mandatory. 


\section{International Journal of Science and Research (IJSR) \\ ISSN (Online): 2319-7064}

Index Copernicus Value (2013): 6.14 | Impact Factor (2015): 6.391

Regarding the effectiveness of PGDT practicum implementation, in Somali Region and East and West Hararghea zones of Oromia Region, most of the data showed that there were problems from selection of mentors, training of mentors and tutorial sessions of the student teachers. Thus, the practice is suffering from confusion and challenges. Though the problem is common for all, the extent of the problem in Somali region is extremely sever. This implies that the teachers being trained are not getting the appropriate support in practicum and distance courses and this in turn spoils their quality.

\subsection{Recommendations}

Based on the data collected and the conclusions drawn, the following recommendations were made.

- To practice the PGDT program effectively and to taste its fruits, we strongly believe that the modality should be changed to regular and this first summer shall be the first and the last.

- MOE has to organize a consultative workshop on the processes and practices across universities and REBs

- There should be clear communication between the MOE and REB, so that the stalk holders will play their roles and the program will have owner.

- MOE should urge the REB to select, recruit and send their trainees to universities as stated in guidelines and also the selection and admission criteria shall be respected.

- REBs should form a monitoring or coordinating committee at school level to look after the welfare of the student teachers because they are new to such environments.

- We believe that the scenario is common for all Teacher Training Universities especially Education Colleges, they should forward their concerns as we did to the concerned bodies for plausible intervention.

\section{References}

[1] Curriculum for Beginners. International Journal of Science Education.24 (9). 941-953.

[2] Engida, Temechegn (2002). Reflections on African Science Education for the New Millennium: The Case of the Ethiopian Chemistry.

[3] GCE, The Global Campaign for Education.(2002). A Quality Education For All: Priority Actions for Governments, Donors and Civil Society. GCE Briefing Paper. Obtained from Web site:

[4] George, J., Worrell, P.,Ampersand, J, and Rampaul, B. (2000). Becoming a primary school teacher in Trinidad and Tobago (Part 2, Teaching practices experience of Trainees:

[5] Gustafson .J. and Rowell.M. (1995).Elementary Preservice Teachers: constructing Conception about learning Science, Teaching Science and the nature of Science .International Journal of science Education.17 (5), 589-605.

[6] Hill, G. and Brodin, K.L. (2004). Physical Education Teachers Perceptions of the Adequacy of University course work in preparation for Teaching. Physical Educator, 61(2), http://www.campaignforeducation
[7] Lockheed E. M. and Verspoor, M. A.(1991) Improving Primary Education In Developing countries. World Bank. Washington DC.

[8] MOE (1973) Education Challenge to the Nation. Addis Ababa: Artistic Printers.

[9] MOE (2003). Teacher Education System Overhaul TESO.Handbook. Available@www.tei.edu.et

[10] MOE (2009b). Postgraduate Diploma in Teaching (PGDT), Curriculum Framework for Secondary School Teacher Education Program in Ethiopia. Addis Ababa. Ministry of Education.

[11] MOE (2010a). Education Sector Development IV (ESDP IV),Program Action Plan, (2010/11-2014/15. Addis Ababa. Ministry of Education.

[12] MOE (2011). Postgraduate Diploma in Teaching (PGDT), Practicum Implementation Provisional Guideline. Addis Ababa. Ministry of Education.

[13]Negash, Tekeste (1996). Rethinking Education in Ethiopia. Uppsala: Nordiska Afrikainstitutet

[14] Psacharopoulos, G. (1985). Returns to Education. A Further international Update and Implications. Journal of Human resources, 20 (4), 583.

[15] Tefera, Seyoum (1996). Attempts at Educational Reform: A Top-Down or a Bottom-Up Reform. Ethiopian Journal of Education, XVI (1), 1-37.

[16] TGE -Transitional Government of Ethiopia (1994). Education Sector Strategy. Addis Ababa: EMPDA.

[17] UNESCO. (1997). educating for Sustainable Future: A Tran disciplinary Vision For Concerted Action.EPD97/CONF.401/.UNESCO.

[18] UNESCO. (2005). EFA Global Monitoring Report. The Quality Imperative. UNESCO.Paris. 